\title{
Platelet-rich plasma for regeneration of neural feedback pathways around dental implants: a concise review and outlook on future possibilities
}

\author{
Yan Huang ${ }^{1,2}$, Michael M Bornstein ${ }^{1,3,4}$, Ivo Lambrichts ${ }^{5}$, Hai-Yang $\mathrm{Yu}^{2}$, Constantinus Politis ${ }^{1}$ \\ and Reinhilde Jacobs ${ }^{1}$
}

\begin{abstract}
Along with the development of new materials, advanced medical imaging and surgical techniques, osseointegrated dental implants are considered a successful and constantly evolving treatment modality for the replacement of missing teeth in patients with complete or partial edentulism. The importance of restoring the peripheral neural feedback pathway and thus repairing the lack of periodontal mechanoreceptors after tooth extraction has been highlighted in the literature. Nevertheless, regenerating the nerve fibers and reconstructing the neural feedback pathways around osseointegrated implants remain a challenge. Recent studies have provided evidence that platelet-rich plasma (PRP) therapy is a promising treatment for musculoskeletal injuries. Because of its high biological safety, convenience and usability, PRP therapy has gradually gained popularity in the clinical field. Although much remains to be learned, the growth factors from PRP might play key roles in peripheral nerve repair mechanisms. This review presents known growth factors contributing to the biological efficacy of PRP and illustrates basic and (pre-)clinical evidence regarding the use of PRP and its relevant products in peripheral nerve regeneration. In addition, the potential of local application of PRP for structural and functional recovery of injured peripheral nerves around dental implants is discussed.
\end{abstract} International Journal of Oral Science (2017) 9, 1-9; doi:10.1038/ijos.2017.1; published online 10 March 2017

Keywords: neural regeneration; osseoperception; peripheral nerve degeneration; peri-implant sensory feedback; platelet-rich plasma

\section{INTRODUCTION}

As one of the major advances in dental medicine in the past 50 years, dental implants have revolutionized the traditional way of oral rehabilitation. By reestablishing physiological function and even promoting general health, treating complete or partial edentulous patients using dental implants is regarded as an ideal treatment plan today. ${ }^{1}$ In addition to these generally known benefits of replacing lost teeth with dental implants, the natural periodontal ligament and the intimate contact between collagen fibers and Ruffini mechanoreceptive terminals (e.g., myelinated and unmyelinated nerve fibers) are thought to be inevitably impaired by tooth loss. ${ }^{2}$ However, this latter assumption is contradicted by a phenomenon, first described by Professor P-I Brånemark, in which lower-limb amputees walking while wearing bone-anchored prostheses are able to differentiate between different soils. ${ }^{3-5}$ Furthermore, patients with oral implants have reported a gradual increase in their tactile function over time. ${ }^{6}$

This phenomenon, known in the literature as "osseoperception", originates from the bone in the immediate vicinity of the inserted implants. ${ }^{4}$ In general terms, this tactile perception has been defined as the mechanosensibility associated with osseointegrated implant rehabilitation, which can be transduced by various kinds of mechanoreceptors located in the oro-facial region, such as in the muscle, joints, oral mucosa, periosteal tissues and skin. ${ }^{7}$ An animal study from our group demonstrated that myelinated nerve fibers densely populated the peri-implant mucosa and apical regions and, to a lesser extent, were also detected in the woven bone and osteons near the implant threads, ${ }^{8}$ indicating that the peri-implant soft tissue can play a role in the repair and regeneration of sensory nerve endings. Recent reports

\footnotetext{
${ }^{1}$ OMFS IMPATH Research Group, Department of Imaging and Pathology, Faculty of Medicine, KU Leuven and Oral and Maxillofacial Surgery, University Hospitals Leuven, Leuven, Belgium; ${ }^{2}$ State Key Laboratory of Oral Diseases, National Clinical Research Center for Oral Diseases, West China Hospital of Stomatology, Sichuan University, Chengdu, China; ${ }^{3}$ Section of Dental Radiology and Stomatology, Department of Oral Surgery and Stomatology, University of Bern, Bern, Switzerland; ${ }^{4}$ Applied Oral Sciences, Faculty of Dentistry, The University of Hong Kong, Prince Philip Dental Hospital, Hong Kong, China and ${ }^{5}$ Group of Morphology, Biomedical Research Institute, Hasselt University, Diepenbeek, Belgium

Correspondence: Professor HY Yu, State Key Laboratory of Oral Diseases, National Clinical Research Center for Oral Diseases, West China Hospital of Stomatology, Sichuan University, Chengdu 610041, China

E-mail: yhyang6812@foxmail.com

Professor R Jacobs, OMFS IMPATH Research Group, Department of Imaging and Pathology, Faculty of Medicine, KU Leuven and Oral and Maxillofacial Surgery, University Hospitals Leuven, Kapucijnenvoer 33, Leuven 3000, Belgium

E-mail: reinhilde.jacobs@kuleuven.be

Accepted 17 January 2017
} 
even show that an osseointegrated implant can at least partly restore the peripheral neural feedback pathway. ${ }^{9-10}$

Clinical evidence in favor of the osseoperception concept includes signs of the existence of regenerated nerve fibers around implant threads, ${ }^{11}$ recovery of tactile function ${ }^{12}$ and even activation of the primary sensorimotor cortex while dental implants are mechanically stimulated. ${ }^{13}$ These findings add to the evidence that peri-implant nerve tissue possesses the inherent capacity to regenerate after tooth extraction, albeit in most cases on a quite basic level.

In an attempt to further enhance osseoperception, novel treatment strategies have been proposed involving reconstruction of the periimplant ligament, ${ }^{14}$ transplantation of Schwann cells (SCs), ${ }^{15}$ injection of neuropeptides (e.g., calcitonin gene-related peptide- $\alpha)^{16}$ and various implant placement and loading protocols. ${ }^{8}$ However, none of the aforementioned principles have reached true proof-of-principle status, and their potential clinical use remains questionable to date.

On the basis of the currently available evidence, platelet-rich plasma (PRP), which contains growth factors that positively influence neural cell survival, might have the potential to promote peripheral nerve regeneration. ${ }^{17-18}$ Thus, the following review summarizes the state-ofthe-art application of PRP for recovery of injured peripheral nerves and offers an outlook on possible future use as an emerging strategy for osseoperception. The articles cited in the review, published up to the 15 November 2016 and including electronic early-release publications, were acquired using three databases: MEDLINE (PubMed), Web of Science (ISI Web of Knowledge) and OpenGrey (System for Information on Grey Literature in Europe).

\section{PRP TREATMENT: PREPARATION AND BIOLOGICAL CHARACTERISTICS}

As a promising autogenous graft, PRP has been a focus in regenerative medicine in recent years. Following the publications by Whitman et al. ${ }^{19}$ and Marx et al., ${ }^{20}$ the application of PRP has gained increasing popularity in the medical field, especially in oral and maxillofacial surgery. In the past decade, PRP has been developed via a variety of commercial and home-made techniques, and thus various forms of PRP exist, including plasma rich in growth factors (PRGFs), ${ }^{21}$ cell separator
PRP, ${ }^{22}$ Choukroun's platelet-rich fibrin,${ }^{23}$ concentrated PRP,${ }^{24}$ plateletleukocyte gel ${ }^{25}$ and simplified PRP products called concentrated growth factors. ${ }^{26}$ In daily practice, most clinicians apply one or two specific PRP products according to their own experience, in liquid or solid form.

To avoid confusion in the interpretation of published results, there is a clear need to accurately describe the products that are tested and to try to classify them accordingly (Table 1). ${ }^{27-29}$ Ehrenfest et al. suggested that the various platelet concentrates can be classified into four main categories, depending on the known leukocyte content and fibrin architecture: ${ }^{30-32}$ pure platelet-rich plasma (P-PRP), leukocyte- and platelet-rich plasma (L-PRP), pure platelet-rich fibrin (P-PRF), and leukocyte- and platelet-rich fibrin (L-PRF). Given this variety of preparations and applications of platelet concentrates, ${ }^{32}$ studies do not always adhere to the proposed classification, which leads to inconsistent results and confusion in comparing the efficacy of PRP products. Thus, the term "PRP" is used in the present review to include all known terms, and specific names will be used only when applicable.

In general, PRP is derived from the centrifugation of autologous whole blood and finally forms a gel-like structure when mixed with thrombin and calcium chloride. ${ }^{33}$ After the activation of platelets, a cocktail of growth factors with mitogenic and chemotactic characteristics are induced and released from the platelets' $\alpha$-granules, an organelle critical for wound healing. Instead of the effect being limited by the use of a single growth factor, the multiple factors together mimic the complex situation of natural tissue repair and improve processes such as angiogenesis, inflammation and the immune response. There is also convincing evidence that the survival of sensory neurons depends on multiple neurotrophic factors acting synergistically or in a defined sequence. ${ }^{34}$ The antimicrobial potential of PRP, owing to the leukocytes and neutrophils it contains, was also reported in a recent systematic review of available preclinical evidence and is one of PRP's critical characteristics in controlling postoperative infections at surgical sites. ${ }^{35}$

A further advantage is that all growth factors, proteins and cytokines from PRP are autologous and non-toxic. This treatment using the patient's own blood could avert complex ethical issues, immunological

Table 1 Current classification of platelet concentrated materials and their key characteristics in clinic application

\begin{tabular}{|c|c|c|c|c|c|}
\hline Classification & Contents & Pros & Cons & Preparation & $\begin{array}{l}\text { Concentration of pla- } \\
\text { telets and leukocytes }\end{array}$ \\
\hline P-PRP & $\begin{array}{l}\text { Platelets with low-density fibrin network after } \\
\text { activation, without leukocytes }\end{array}$ & $\begin{array}{l}\text { Liquid solution or as gel after } \\
\text { activation can be injected or } \\
\text { placed on wound }\end{array}$ & $\begin{array}{l}\text { Dissolves quickly } \\
\text { like a fibrin glue }\end{array}$ & $\begin{array}{l}\text { Two-step centrifugation, with } \\
\text { anticoagulant and blood } \\
\text { activator }\end{array}$ & $\begin{array}{l}\text { Platelets: } \\
500 \times 10^{3} \mu \mathrm{L}^{-1} \\
\text { leukocytes: } \\
0.2 \times 10^{3} \mu \mathrm{L}^{-1}\end{array}$ \\
\hline L-PRP & $\begin{array}{l}\text { Platelets with low-density fibrin network and } \\
\text { leukocytes }\end{array}$ & $\begin{array}{l}\text { Liquid solution or as gel after } \\
\text { activation can be injected or } \\
\text { placed on wound }\end{array}$ & $\begin{array}{l}\text { Dissolves quickly } \\
\text { like a fibrin glue }\end{array}$ & $\begin{array}{l}\text { Two-step centrifugation, with } \\
\text { anticoagulant and blood } \\
\text { activator }\end{array}$ & $\begin{array}{l}\text { Platelets: } \\
500 \times 10^{3} \mu \mathrm{L}^{-1} \\
\text { leukocytes: } \\
20 \times 10^{3} \mu \mathrm{L}^{-1}\end{array}$ \\
\hline P-PRF & $\begin{array}{l}\text { Platelets with high-density fibrin network and } \\
\text { without leukocytes }\end{array}$ & $\begin{array}{l}\text { Only exist as gel after } \\
\text { activation }\end{array}$ & $\begin{array}{l}\text { Solid gel, cannot } \\
\text { be injected }\end{array}$ & $\begin{array}{l}\text { Two-step centrifugation, with } \\
\text { anticoagulant and blood } \\
\text { activator }\end{array}$ & $\begin{array}{l}\text { Platelets: } \\
400 \times 10^{3} \mu \mathrm{L}^{-1} \\
\text { leukocytes: } \\
100-600 \mu \mathrm{L}^{-1}\end{array}$ \\
\hline L-PRF & $\begin{array}{l}\text { Platelets and half of the leukocytes (mainly } \\
\text { lymphocytes), with a high-density fibrin network }\end{array}$ & $\begin{array}{l}\text { Gel without anticoagulant; } \\
\text { natural blood clot }\end{array}$ & $\begin{array}{l}\text { Solid gel, cannot } \\
\text { be injected }\end{array}$ & $\begin{array}{l}\text { One-step centrifugation, without } \\
\text { anticoagulant or blood activator }\end{array}$ & $\begin{array}{l}\text { Platelets: } \\
400 \times 10^{4} \mu \mathrm{L}^{-1} \\
\text { leukocytes: } \\
60 \times 10^{3} \mu \mathrm{L}^{-1}\end{array}$ \\
\hline
\end{tabular}

L-PRF, leukocyte- and platelet-rich fibrin; L-PRP, leukocyte- and platelet-rich plasma; P-PRF, pure and platelet-rich fibrin; P-PRP, pure and platelet-rich plasma. 
rejections or similar adverse effects known to exist with allograft or xenograft materials. Compared to an artificially synthesized single growth factor or most of the other biomaterials available on the market, the clinical collection and preparation of PRP are convenient, efficient and economic. ${ }^{36}$ In addition, the gel-like consistency of PRP is beneficial for its application into small bone defects, and it is not easily washed away from the surgical site.

\section{The role of growth factors from PRP on nerve regeneration}

A growing body of studies has demonstrated that topical PRP application is effective in soft-tissue healing and bone regeneration in implant surgery. ${ }^{37-39}$ The potential of PRP in modulating soft- and hard-tissue formation and regeneration depends on the levels of released growth factors. ${ }^{40}$ For peripheral nerve regeneration, as summarized in Table 2, ${ }^{41-52}$ various known cytokines and growth factors within platelet-rich plasma, including transforming growth factor- $\beta$ (TGF- $\beta$ ), platelet-derived growth factor, vascular endothelial growth factor, insulin-like growth factor and basic fibroblast growth factor (bFGF), have been discussed as being crucial for cell proliferation and differentiation, stimulation of angiogenesis and scar control in the process of regenerating peripheral nerve structures. Although the mechanism by which these growth factors work together and interact efficiently for wound healing remains incompletely understood, ${ }^{53}$ preliminary studies have already demonstrated positive effects from PRP acting as a pool of growth factors.

\section{Evidence from clinical studies}

When traumatic gaps of nerve structures are $<3 \mathrm{~cm}$ long, PRP has shown the ability to induce nerve regeneration. ${ }^{17}$ To regenerate axons across nerve gaps longer than $3 \mathrm{~cm}$, it is suggested that PRP be applied with a bridging graft material that both supports and promotes axon regeneration. Two case reports have suggested that a fibrin clot could help with full functional recovery after surgical repair of a totally transected abducens nerve. ${ }^{54}$ PRF together with a collagen tube has been shown to induce appropriate sensory and motor recovery across a $12-\mathrm{cm}$-long ulnar nerve gap. ${ }^{55}$ A case report demonstrated PGRF's therapeutic potential for the treatment of common perineal nerve palsy associated with multiple ligament injuries of the knee. ${ }^{56}$ A report of a case in which PRGF was used for the treatment of bisphosphonate-related osteonecrosis of the jaw showed recovered sensitivity and partially regenerated bone in a 1-year follow-up. ${ }^{57}$ The fact that defects around dental implants are normally not as large as peripheral nerve defects might make the regeneration of peri-implant nerve fibers more feasible because of the reduced need for added biomaterials; PRP can be used alone.

Investigations in the field of functional neural recovery have reported that PRP prompts the re-establishment of sensitivity within 2 weeks of observation for patients with peripheral neuropathy induced by leprosy ${ }^{58}$ and improves upper-limb function by 3-month follow-up. ${ }^{59}$ Similarly, a preliminary clinical study found that, when a modified inferior alveolar nerve lateralization technique was performed, the covering of the inferior alveolar nerve with platelet-rich materials and a collagen membrane could result in accelerated recovery of sensation within the first 6 months as evaluated by subjective two-point discrimination and static light touch. ${ }^{60}$ Furthermore, this treatment method could significantly reduce the duration of the initial discomfort. A recent split-mouth designed human study ${ }^{61}$ indicated that the use of L-PRF as a socket-filling material could achieve not only the preservation of horizontal and vertical ridge dimension but also the regrowth of blood vessels and nerve axons
(Figure 1) in the anterior maxillary regions at 3 months after tooth extraction.

However, a randomized, controlled and single-blinded clinical study found that PRP drops alone had no positive effect on the recovery of corneal sensitivity after laser therapy, although beneficial effects were observed in the promotion of epithelial healing. ${ }^{62}$ This finding is probably due to the limited bioavailability of growth factors on the intact corneal stroma when the substance is topically administered.

It is also worth mentioning that, for ethical reasons, histological analyses of human samples to investigate neural regeneration are rare. In most cases, functional and morphologic evaluations, such as ankle stance angle, walking track analysis and electrophysiologic tests, are not only the recommended methods but also the few feasible options for studies of peripheral nerve regeneration. ${ }^{63}$ For clinical situations in implant dentistry, oral psychophysical studies and magnetic resonance imaging tests ${ }^{5}$ are usually performed to evaluate and monitor the osseoperception around implants.

\section{Evidence from basic research}

Although relatively few human trials have involved PRP therapy, there is mounting evidence from in vitro and animal experiments. PRP has been used to study the effect of stimulating neural regeneration of the rat facial nerve, ${ }^{64}$ rat sciatic nerve, ${ }^{65-74}$ rat cavernous nerve, ${ }^{75-76}$ guinea pig facial nerve, ${ }^{77}$ rabbit sciatic nerve, ${ }^{78}$ dog anterior cruciate ligament ${ }^{79}$ and rat spinal cord. ${ }^{80}$ These studies presented positive results regarding functional nerve recovery, ${ }^{64,66-77,80}$ regeneration of axons, ${ }^{64-65,70-72,75-76}$ g-ratio (an index of optimal axonal myelination), ${ }^{67}$ thickness of the myelin sheath, ${ }^{66,70,77-78}$ nerve conduction velocity, ${ }^{78}$ revascularization and reinnervation, ${ }^{79}$ and axon diameter, ${ }^{69,70,80}$ with observation periods ranging from 2 to 12 weeks postoperatively.

In addition, two recent studies have suggested that concentrated growth factors (CGFs) could promote not only the migration of SCs in vitro ${ }^{81}$ but also functional recovery in a rat model of sciatic nerve crush injury. ${ }^{18}$ By contrast, one study ${ }^{82}$ reported that platelet gel with a collagen tube conduit did not have a beneficial effect on rat sciatic nerve regeneration 12 weeks after microsurgical reconstruction. However, 2 years later, the same group ${ }^{83}$ observed that the same gel could have a positive effect on nerve repair. The discrepancy between the studies may be due to differences in histological processing or to excessive stimulation of collagen formation in the initial study by growth factors from the platelet gel, including TGF- $\beta$ and bFGF.

Although numerous relevant animal studies have been carried out, only a few of these investigations clearly provided specific platelet concentrations. ${ }^{67-68,72,84-86}$ In rat studies, the average whole-blood platelet count has been reported to be $478.12 \times 10^{3} \mu \mathrm{L}^{-1}$, and the average platelet count of PRP was $3221.34 \times 10^{3} \mu \mathrm{L}^{-1,72}$ whereas the effective concentration of platelets in another investigation using rats was $1500 \times 10^{3}$ platelets per $\mu \mathrm{L} .{ }^{67}$ Similarly, in an ovine model, restoration of motor function at 12 weeks after peroneal nerve compression injury was achieved using scaffolds and PRGF injections; the platelet count was $202 \times 10^{3}-349 \times 10^{3} \mu \mathrm{L}^{-1.86}$ Considering the relatively wide range of platelet counts in these studies, it would be of importance for future studies to evaluate in more detail the effective range of platelet concentration, whole-blood platelet counts and, if applicable, their growth factor levels.

Furthermore, an in vitro study indicated that the appropriate concentration of PRP from rats, with an average whole-blood 
Table 2 Summary of potential cytokines and growth factors from $\alpha$-granules within platelet-rich plasma

\begin{tabular}{|c|c|c|c|}
\hline Growth factors & Function & Mechanisms & References \\
\hline $\begin{array}{l}\text { Transforming growth } \\
\text { factor- } \beta \text { (TGF- } \beta \text { ) }\end{array}$ & $\begin{array}{l}\text { Stimulates endothelial chemotaxis and angiogenesis } \\
\text { Regulates mitogenic effects of other growth factors } \\
\text { (nerve growth factor, brain derived neurotrophic factor, } \\
\text { etc) } \\
\text { Induces undifferentiated mesenchymal cell }\end{array}$ & $\begin{array}{l}\text { Secrets into the local nerves by damaged neurons, } \\
\text { invading macrophages and degenerated schwann cells (SCs) } \\
\text { during Wallerian degeneration } \\
\text { Activates SCs and recruit macrophages to the injury site of } \\
\text { distal nerve stumps }\end{array}$ & $\begin{array}{l}\text { Unsicker and } \\
\text { Strelau }{ }^{41} \\
\text { Gordon et al. }{ }^{42} \\
\text { Sulaiman and } \\
\text { Dreesen } 43\end{array}$ \\
\hline
\end{tabular}

proliferation

Stimulates neurite outgrowth and regulates

differentiation of SCS

Inhibits macrophage and lymphocyte proliferation.

Platelet-derived growth Stimulates trophic activity on neurons

factor (PDGF)

\section{Induces SCs proliferation, differentiation and myelin} formation

Mitogenetic for mesenchymal cells and osteoblasts. Involved in the wound healing of hard and soft tissues and for central nervous system development

Stimulates hyaluronan and glycosaminoglycans

(components of the extracellular matrix)

Vascular endothelial growth factor (VEGF)

Insulin-like growth factor-1 (IGF-1)

factor (bFGF)

\section{Enhances angiogenesis and vessel permeability}

Regulates cell proliferation and mediates antiapoptotic effect

Stimulates mitogenesis for endothelial cells

Promotes blood vessel growth, neurogenesis and neuroprotection

Initiates the formation of bud growth

Supports the forward extension of the nerve fibers

Suppresses apoptosis in motor, sensory and

sympathetic neurons

Stimulates protein synthesis

Contributes to embryonic development, angiogenesis and wound healing

Facilitates neuroprotection and SCs regeneration
Acts on the factor tyrosine kinases (RTKs) and the downstream PI3K and mitogen-activated protein (MAP) kinase signaling pathways

Stimulates chemotaxis of neutrophils and macrophages

to the injured sites and participates in tissue re-epithelialization and/ or angiogenesis

Induces injury-related angiogenesis by connecting to endothelial transmembrane receptors identified as fms-like tyrosine kinase (FLT-1), fetal liver tyrosine kinase receptor (FLK-1) and neurophilin-1

Via the PI3K pathway, induces SCs to synthesize of two fatty acids that initiates the process of myelination Secreted in the vicinity of the injured nerve sites and its receptors are mainly expressed on axon, nerve terminals, SCs and motor neuron cell bodies, promoting early recovery of sensation

After peripheral nerve injury, bFGF and its high-affinity tyrosine kinase receptor FGFR-3 are upregulated in sensory neurons and at the lesion site of the nerve, inducing angiogenesis and accelerates wound closure
Mackenzie and Ruhrberg 48 Hermann and Zechariah $^{49}$

Liang et al. ${ }^{50}$ Nagata et al. ${ }^{51}$

Grothe and Nikkhah $^{52}$
Graham et al. ${ }^{44}$ Yamazaki et al. 45 Burnouf et al. ${ }^{46}$ Hellman et al. ${ }^{47}$ platelet count of $536 \times 10^{3} \mu \mathrm{L}^{-1}$ and a PRP platelet count of $3481.75 \times 10^{3} \mu \mathrm{L}^{-1}$, has the potential to stimulate proliferation and migration of SCs, which are regarded as the primary structural and functional cells of the peripheral nervous system. ${ }^{85}$ An in vitro investigation noted that the addition of PRP, with a mean wholeblood platelet count of $186.35 \times 10^{3} \mu \mathrm{L}^{-1}$ and a PRP platelet count of $1237.28 \times 10^{3} \mu \mathrm{L}^{-1}$, could facilitate the potential use of human adipose-derived stem cells in nerve regeneration. ${ }^{84}$

Thus far, most of the in vivo and in vitro results mentioned above have supported promising future prospects for local application of PRP, CGF or PRGF in functional axon recovery; however, the efficacy of PRF in the regeneration of peripheral nerves is still questionable, and the related studies are far fewer than those using PRP. As reported by an in vivo study, PRP and PRF were both effective in the functional recovery of a 10-mm sciatic nerve injury 90 days after surgery, with a mean whole-blood platelet count of $460 \times 10^{3} \mu \mathrm{L}^{-1}$, a PRP platelet count of $2623 \times 10^{3} \mu \mathrm{L}^{-1}$ and a mean PRF platelet count of $35 \times 10^{3} \mu \mathrm{L}^{-1}$, albeit without a significant difference between axonal diameter and myelin thickness. ${ }^{68}$ In contrast, PRF failed to increase functional recovery in a $5-\mathrm{mm}$ sciatic nerve gap as shown by functional, histopathologic and electrophysiologic analyses. ${ }^{87}$ Although the PRF in these two studies was produced using the same protocol described by Choukroun et al., ${ }^{23}$ the effective concentrations of activated platelets and released growth factors were not examined in the latter study, making it almost impossible to know whether the observed differences were due to inter-individual variation or the preparation method.

\section{HYPOTHESIS: PERIPHERAL NERVE REGENERATION AFTER EXTRACTION USING PRP AND IMMEDIATE IMPLANT PLACEMENT}

After the extraction of teeth, mechanoreceptors in the periodontal ligament are subject to immediate degeneration. A novel idea to stimulate peripheral nerve regeneration after tooth loss would be to add a multitude of growth factors from autologous PRP together with an implant placement immediately after tooth extraction to overcome degenerative neural processes. Gene transcription, neural progenitor cells and nerve remodeling are dynamically regulated and induced in the regeneration cycle and in response to growth factors and respective signaling pathways, such as phosphatidylinositol-3 kinase (PI3K)-Akt and Ras/extracellular signal-regulated kinase, that are required for neurite survival and outgrowth. ${ }^{88}$ The whole process could not only directly enhance the regeneration of nerve fibers but also indirectly induce angiogenesis, myelin formation, and SC proliferation and differentiation, and even activate potential stem cell lines in the region of the implants. 

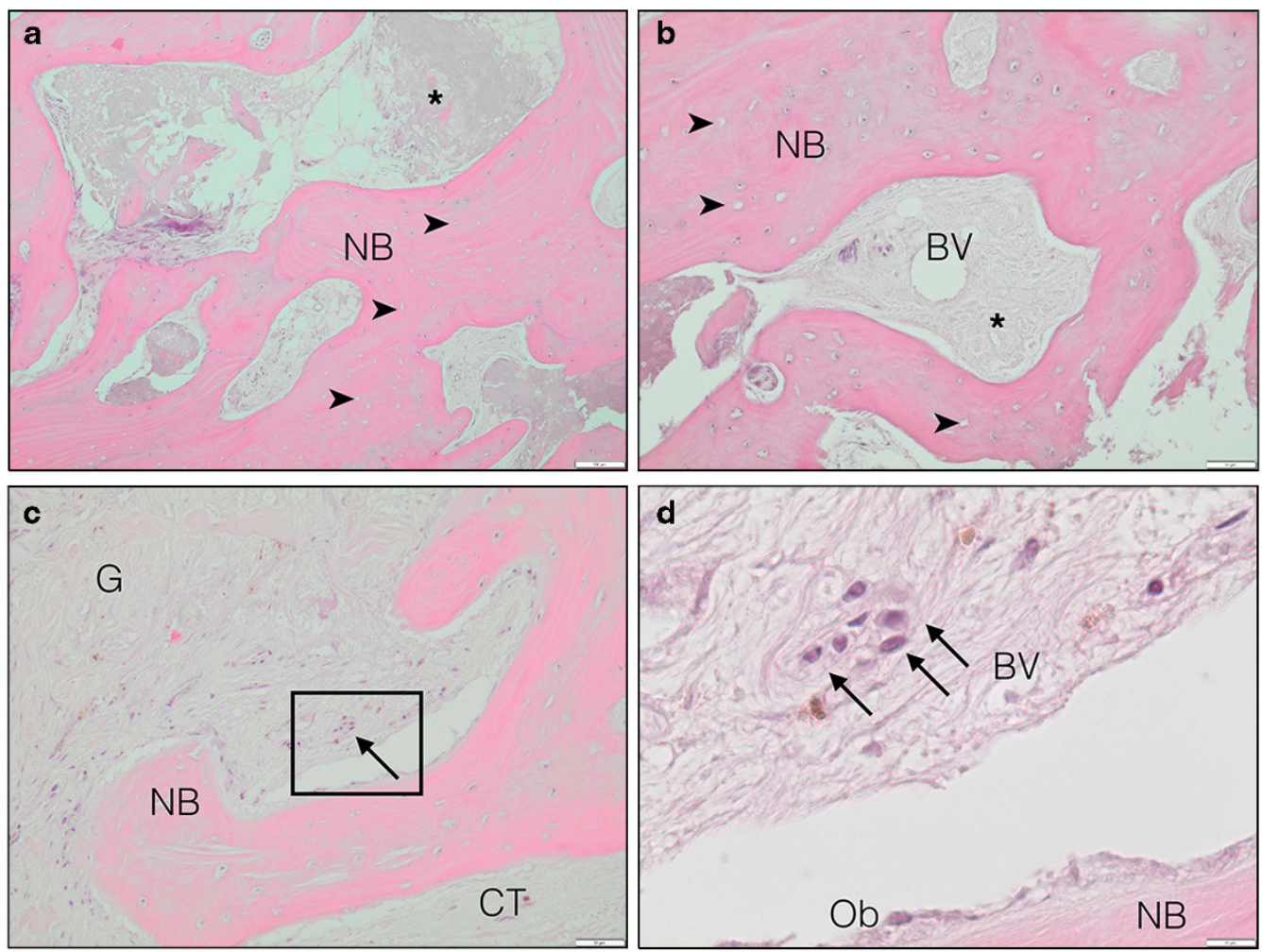

Figure 1 Light micrograph showing the histomorphological appearance of tissue regeneration in the anterior maxilla at 3 months after extraction and autologous L-PRF application before the placement of the dental implant. In (a) and (b), L-PRF (indicated by *) and fibrovascular tissue are surrounded by newly generated bone tissue (NB) with empty osseous lacunae (indicated by arrowheads). (c) A group of regenerated nerve axons (indicated by arrows) in the connective tissue next to the newly generated bone area. (d) A magnification of the selected box region in (c) shows the morphometric details of myelinated nerve fibers. Scale bars, $100 \mu \mathrm{m}$ (a); $50 \mu \mathrm{m}$ (b, c); and $10 \mu \mathrm{m}$ (d). Hematoxylin and eosin staining, courtesy of Ms Ana Castro Sarda and Ms Sanne Deprez, Department of Oral Health Sciences, KU Leuven. BV, blood vessel; CT, connective tissue; G, gingiva; L-PRF, leukocyte- and platelet-rich fibrin; Ob, osteoblast.

Over time, this remodeling process, which functions in a synergistic way, might even increase the metabolic balance of regenerated tissues during the establishment of osseoperception and promote proprioceptive sensory feedback, enabling a well-coordinated masticatory function. This might avoid overload during masticatory function and help maintain the overall health of the temporo-mandibular joint and neuromuscular system in patients treated with a dental implant (for more detail see Figure 2).

\section{IMPLICATIONS FOR FUTURE STUDIES}

Most of the research on dental implants has been focused on osseointegration and bone regeneration due to limitations in bone availability in the upper or lower jaw prior to planned implant treatment. Nevertheless, not only does rehabilitation with dental implants aim to acheive primary or secondary implant stability and osseointegration, but a functional implant resulting in wellcoordinated masticatory function is also of great importance to ensure long-term success and patient satisfaction. Therefore, the relevance and accomplishment of osseoperception will hopefully receive more attention in research and daily clinical practice in the future. The following paragraphs highlight some areas where more knowledge is urgently needed.

The process of PRP preparation and its therapeutic concentration Although autologous blood concentrations may offer promising treatment options for peripheral nerve injury in the oral cavity, few studies have focused on the effects of PRP therapy on peri-implant sensory feedback. It is essential to realize that a large number of variables may influence the therapeutic efficacy of PRP treatment, which may partly explain the conflicting results in different experiments. ${ }^{89}$

One of these important factors is the process of PRP preparation itself, which may result in different concentrations of platelets among patients treated and thus in broad variability of the growth factor ratio. ${ }^{90}$ Higher concentrations of platelets in PRP may not necessarily result in positive cell proliferation; ${ }^{91}$ instead, an optimal (not yet defined) concentration range of PRP would help to keep those growth factors active and functioning well for a longer time period. Hence, it is reasonable to assume that an ideal PRP concentration-perhaps even tailor-made for each patient treated-could maximize the therapeutic benefits of nerve regeneration and wound healing.

Other factors contributing to the unpredictability and complexity of the therapeutic efficacy of PRP in peripheral nerve regeneration are differences in the method of activation (calcium chloride or thrombin), mode of application (injection or implantation of a PRP gel), storage temperature $\left(-80^{\circ} \mathrm{C}\right.$ frozen or room temperature) and frequency of application.

A potential therapeutic level of platelet concentration for bone and soft-tissue regeneration has been reported, namely, $1000 \times 10^{3} \mu \mathrm{L}^{-1}$ (four- to fivefold the baseline platelet numbers). ${ }^{92}$ However, less is known about the optimized dose-response curve regarding nerve regeneration. Cell culture experiments ${ }^{85}$ have shown that $2.5 \%-20 \%$ 


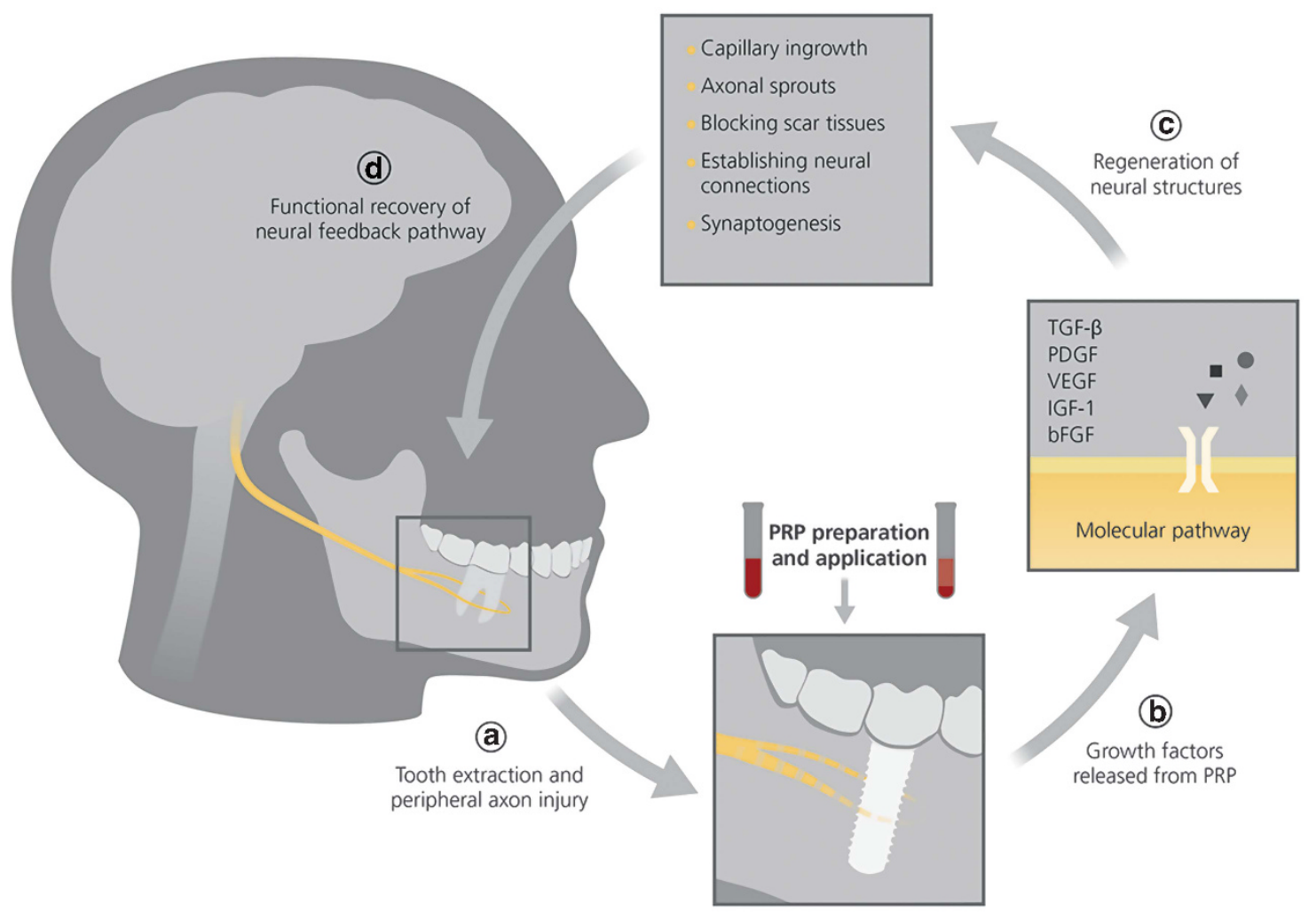

Figure 2 Schematic regeneration model of the potential neural feedback pathways around dental implants enhanced by PRP injection. (a) In the craniomaxillofacial region, the extraction of teeth causes acute damage, known as Wallerian degeneration, to the peripheral axons (mainly from branches of the trigeminal nerve). The injection of PRP into the local sites of tooth loss may help the regeneration of peri-implant nerve tissues. (b) Activated PRP initially releases a group of growth factors (see Table 1 for a detailed explanation of their function and roles) into the peri-implant area, which could bind to individual receptors and then activate their molecular pathways. In addition, these growth factors could work synergistically to trigger repair mechanism in a more complex way. (c) The functioning of signaling molecules in nerve cells leads to a series of regeneration of neural structures in the region of the implants, which could be clinically characterized by restoration of simple function around dental implants, for example, thermal and nociceptive sensation. (d) As a consequence of nerve regrowth and reinnervation, the cortical adaptive processes of the feedback pathway are expected to exhibit improved physiological and psychological integration of dental implants. bFGF, basic fibroblast growth factor; IGF-1, insulin-like growth factor-1; PDGF, platelet-derived growth factor; TGF- $\beta$, transforming growth factor- $\beta$; VEGF, vascular endothelial growth factor.

PRP $\left(87.5 \times 10^{3}-700 \times 10^{3} \mu \mathrm{L}^{-1}\right)$ from Sprague-Dawley rats could significantly stimulate SC proliferation and migration in a concentration-dependent manner compared to untreated controls. However, when higher PRP concentrations $\left(40 \%, 1400 \times 10^{3} \mu \mathrm{L}^{-1}\right)$ are used, the above-mentioned effects on SCs are suppressed. The present study suggests that there may exist different types of dose responses, reaction rates or complicated interactions between nerve and bone regeneration when PRP products are used.

\section{Timing of treatment}

It has been suggested that muscle tissue could progressively transform into irreversible fibrosis if it is not reinnervated within 1-2 years. ${ }^{17}$ Therefore, the timing of the regenerative intervention seems to be another factor influencing the overall treatment strategy, ${ }^{93}$ after which the target tissue may lose the ability to be reinnervated. However, regarding the immediate and delayed implant placement protocols, there are insufficient data exhibiting obvious differences in the innervation of peri-implant tissues between the two protocols. ${ }^{5}$ More recently, our group observed in a randomized split-mouth study that immediate implant placement and an immediate loading protocol were more likely to lead to optimized peri-implant reinnervation, ${ }^{8}$ suggesting that the timing of treatment for peri-implant reinnervation is a crucial issue to consider when using PRP products.
Because of the short life of platelets — approximately 5-7 days-the effect of PRP on bone repair may be active only in the early stage of wound healing. ${ }^{94}$ As a practical example of the importance of timing when applying PRP in oral surgery, immediately after tooth extraction, in the initial phase of acute axon injury, application of PRP therapy might be valuable for maximizing the neural regeneration and thus for prevention of an excessive load of dental implants. On the other hand, for patients who lost their teeth a long time ago, it might be more effective to combine certain stem cells with PRP therapy in order to maintain continuous availability of the bioactive effects.

\section{Animal models for feasibility experiments}

Despite more reliable and accurate results from human clinical trials, for ethical reasons, preclinical experiments are indispensable to the study of PRP therapy for peripheral nerve injury and regeneration. Appropriate animal models, chosen according to various objectives, are likely to produce convincing and clinically relevant results. Thus, it is important to use an animal model with characteristics comparable to those of the ultimate treatment cohort, ${ }^{95-96}$ including common aspects of anatomy, physiology, histology, pathology and even gene expression. For research in implant dentistry, the animal model should have relatively large teeth and extraction sockets that are convenient for surgery, and it should be possible to take radiographs at the 
surgical site during follow-up. It is also desirable for the animal model to be inexpensive, readily available and easy to anesthetize.

A small variety of animal models, including dogs, mini-pigs and non-human primates, are frequently used in analyzing bone-implant interactions owing to their similarity to human bone physiology and pathology. ${ }^{97-98}$ Although non-human primates offer the most similarity to human bone with respect to anatomy and physiology, minipigs are more widely used because of less critical ethical issues and low purchase and maintenance costs, in addition to easy handling. Unlike pigs, dogs (the "canine model") with stand repetitive blood sampling during PRP preparation, and their mandibles are large enough to receive commercial implants. Furthermore, the characteristics of human bone have been reported to be better approximated by the properties of dog bone in comparison to that of pigs, cows, sheep, chicken and rats. ${ }^{99}$ Therefore, the canine model should be regarded as the preferred animal model in experimental research using PRP.

\section{CONCLUSIONS}

Taken together, current evidence from in vitro and animal experiments and preliminary clinical trials has supported the possibility that peri-implant sensory feedback can be modified and promoted by various growth factors released from autologous PRP. Additional studies are needed to prove the hypothesis that combining PRP with dental implants is an effective and safe treatment concept to convey peripheral neural signals to the central nervous system in a functional manner and thus improve osseoperception. To maximize the regeneration of injured peripheral nerves around dental implants, several points should be considered in future studies:

1. An optimized preparation of PRP is essential for the biological activity and clinical efficacy of growth factors within PRP. All variables of PRP use, such as the concentration of platelets and growth factors, method of activation, mode of application and frequency of application, should be carefully explored and reported.

2. The exact roles and interactions of the growth factors in PRP remain unclear, which is also the case for newer products based on PRP, such as PRF and CGF.

3. The appropriate timing of intervention is of great importance for optimal nerve regeneration. To maximize the structural and functional recovery of injured nerves in combination with PRP, it might be preferable to insert dental implants immediately after tooth extraction following nerve injury.

4. Considering the advantages and limitations of different animal models, the canine model should be regarded as the preferred animal in preclinical research of PRP treatment.

5. Although not easy to accomplish from a practical perspective, prospective clinical studies with a randomized controlled design would be ideal for analyzing the potential risks and benefits of PRP in promoting osseoperception.

\section{ACKNOWLEDGEMENTS}

We thank Mrs Bernadette Rawyler, medical illustrator, School of Dental Medicine, University of Bern, for the preparation of Figure 2. Fellowship support was received from Research Foundation Flanders (FWO) from the Belgian government and the Sichuan Province Science and Technology Support Program (2016SZ0010).
1 Moraschini V, Poubel LA, Ferreira VF et al. Evaluation of survival and success rates of dental implants reported in longitudinal studies with a follow-up period of at least 10 years: a systematic review. Int J Oral Maxillofac Surg 2015; 44(3): 377-388.

2 Mason AG, Holland GR. The reinnervation of healing extraction sockets in the ferret. J Dent Res 1993; 72(8): 1215-1221.

3 Brånemark $\mathrm{PI}$, Rydevik B, Shalak $\mathrm{R}$ et al. Osseointegration in skeletal reconstruction and joint replacement. Rancho Santa Fe: Second International Workshop on Osseointegration in Skeletal Reconstruction and Joint Replacement, 1994.

4 van Steenberghe D. From osseointegration to osseoperception. J Dent Res 2000; 79(11): 1833-1837.

5 Huang $\mathrm{Y}$, Jacobs R, Van Dessel J et al. A systematic review on the innervation of periimplant tissues with special emphasis on the influence of implant placement and loading protocols. Clin Oral Implants Res 2015; 26(7): 737-746.

6 Jacobs R, Van Steenberghe D. From osseoperception to implant-mediated sensorymotor interactions and related clinical implications. J Oral Rehabil 2006; 33(4): 282-292.

7 Klineberg I, Calford MB, Dreher B et al. A consensus statement on osseoperception. Clin Exp Pharmacol Physiol 2005; 32(1/2): 145-146.

8 Huang $\mathrm{Y}$, van Dessel J, Martens W et al. Sensory innervation around immediately vs. delayed loaded implants: a pilot study. Int J Oral Sci 2015; 7(1): 49-55.

9 Feine J, Jacobs R, Lobbezoo F et al. A functional perspective on oral implants - state-ofthe-science and future recommendations. J Oral Rehabil 2006; 33(4): 309-312.

10 Mishra SK, Chowdhary R, Chrcanovic BR et al. Osseoperception in dental implants: a systematic review. J Prosthodont 2016; 25(3): 185-195.

11 dos Santos Corpas L, Lambrichts I, Quirynen M et al. Peri-implant bone innervation: histological findings in humans. Eur J Oral Implantol 2014; 7(3): 283-292.

12 Kazemi M, Geramipanah F, Negahdari R et al. Active tactile sensibility of single-tooth implants versus natural dentition: a split-mouth double-blind randomized clinical trial. Clin Implant Dent Relat Res 2014; 16(6): 947-955.

13 Habre-Hallage $P$, Dricot L, Hermoye $L$ et al. Cortical activation resulting from the stimulation of periodontal mechanoreceptors measured by functional magnetic resonance imaging (fMRI). Clin Oral Investig 2014; 18(8): 1949-1961.

$14 \mathrm{Choi} \mathrm{BH}$. Periodontal ligament formation around titanium implants using cultured periodontal ligament cells: a pilot study. Int J Oral Maxillofac Implants 2000; 15(2): 193-196.

15 Yuan Q, Gong P, Tan Z. Schwann cell graft: a method to promote sensory responses of osseointegrated implants. Med Hypotheses 2007; 69(4): 800-803.

$16 \mathrm{Ma} \mathrm{L}$, Xiang L, Yao Y et al. CGRP-alpha application: a potential treatment to improve osseoperception of endosseous dental implants. Med Hypotheses 2013; 81(2): 297-299.

17 Dagum AB. Peripheral nerve regeneration, repair, and grafting. J Hand Ther 1998; 11(2): 111-117.

18 Qin J, Wang L, Sun Y et al. Concentrated growth factor increases Schwann cell proliferation and neurotrophic factor secretion and promotes functional nerve recovery in vivo. Int J Mol Med 2016; 37(2): 493-500.

19 Whitman DH, Berry RL, Green DM. Platelet gel: an autologous alternative to fibrin glue with applications in oral and maxillofacial surgery. J Oral Maxillofac Surg 1997; 55(11): 1294-1299.

20 Marx RE, Carlson ER, Eichstaedt RM et al. Platelet-rich plasma: growth factor enhancement for bone grafts. Oral Surg Oral Med Oral Pathol Oral Radiol Endod 1998; 85(6): 638-646.

21 Anitua E. Plasma rich in growth factors: preliminary results of use in the preparation of future sites for implants. Int J Oral Maxillofac Implants 1999; 14(4): 529-535.

22 Weibrich G, Kleis WK, Hafner G et al. Comparison of platelet, leukocyte, and growth factor levels in point-of-care platelet-enriched plasma, prepared using a modified Curasan kit, with preparations received from a local blood bank. Clin Oral Implants Res 2003; 14(3): 357-362.

23 Choukroun J, Adda F, Schoeffler C et al. [Une opportunité en paro-implantologie: le PRF]. Implantodontie 2001; 42: 55-62. French

24 Dohan DM, Choukroun J, Diss A et al. Platelet-rich fibrin (PRF): a second-generation platelet concentrate. Part I: technological concepts and evolution. Oral Surg Oral Med Oral Pathol Oral Radiol Endod 2006; 101(3): e37-e44.

25 Dohan Ehrenfest DM, Bielecki T, Corso MD et al. Shedding light in the controversial terminology for platelet-rich products: platelet-rich plasma (PRP), platelet-rich fibrin (PRF), platelet-leukocyte gel (PLG), preparation rich in growth factors (PRGF), classification and commercialism. J Biomed Mater Res A 2010; 95(4): 1280-1282.

26 Corigliano M, Sacco L, Baldoni E. [CGF-una proposta terapeutica per la medicina rigenerativa.] Odontoiatria 2010; 1: 69-81. Italian

27 Anitua E, Zalduendo M, Troya M et al. Leukocyte inclusion within a platelet rich plasmaderived fibrin scaffold stimulates a more pro-inflammatory environment and alters fibrin properties. PLoS One 2015; 10(3): e0121713.

28 Leitner GC, Gruber R, Neumüller J et al. Platelet content and growth factor release in platelet-rich plasma: a comparison of four different systems. Vox Sang 2006; 91(2): 135-139.

29 Masuki H, Okudera T, Watanebe T et al. Growth factor and pro-inflammatory cytokine contents in platelet-rich plasma (PRP), plasma rich in growth factors (PRGF), advanced platelet-rich fibrin (A-PRF), and concentrated growth factors (CGF). Int J Implant Dent 2016; 2(1): 19.

30 Dohan Ehrenfest DM, Rasmusson L, Albrektsson T. Classification of platelet concentrates: from pure platelet-rich plasma (P-PRP) to leucocyte- and platelet-rich fibrin (L-PRF). Trends Biotechnol 2009; 27(3): 158-167. 
31 Ehrenfest DD, Sammartino G, Shibli JA et al. Guidelines for the publication of articles related to platelet concentrates (platelet-rich plasma-PRP, or platelet-rich fibrin-PRF): the international classification of the POSEIDO. Poseido 2013; 1(1): $17-27$.

32 Dohan Ehrenfest DM. Classification of platelet concentrates (platelet-rich plasma-PRP, platelet-rich fibrin-PRF) for topical and infiltrative use in orthopedic and sports medicine: current consensus, clinical implications and perspectives. Muscles Ligaments Tendons J 2014; 4(1): 3-9.

33 Kuffler DP. Platelet-rich plasma promotes axon regeneration, wound healing, and pain reduction: fact or fiction. Mol Neurobiol 2015; 52(2): 990-1014.

34 Terenghi G. Peripheral nerve regeneration and neurotrophic factors. J Anat 1999; 194(Pt 1): 1-14.

35 Fabbro MD, Bortolin M, Taschieri S et al. Antimicrobial properties of platelet-rich preparations. A systematic review of the current pre-clinical evidence. Platelets 2016; 27(4): 276-285.

36 Siemionow M, Uygur S, Ozturk $\mathrm{C}$ et al. Techniques and materials for enhancement of peripheral nerve regeneration: a literature review. Microsurgery 2013; 33(4): 318-328.

37 Gentile P, Bottini DJ, Spallone D et al. Application of platelet-rich plasma in maxillofacial surgery: clinical evaluation. J Craniofac Surg 2010; 21(3): 900-904.

38 Albanese A, Licata ME, Polizzi B et al. Platelet-rich plasma (PRP) in dental and oral surgery: from the wound healing to bone regeneration. Immun Ageing 2013; 10: 23.

39 Georgakopoulos I, Tsantis S, Georgakopoulos P et al. The impact of platelet rich plasma (PRP) in osseointegration of oral implants in dental panoramic radiography: texture based evaluation. Clin Cases Miner Bone Metab 2014; 11(1): 59-66.

40 Marx RE. Platelet-rich plasma (PRP): what is PRP and what is not PRP. Implant Dent 2001; 10(4): 225-228.

41 Unsicker K, Strelau J. Functions of transforming growth factor-beta isoforms in the nervous system. Cues based on localization and experimental in vitro and in vivo evidence. Eur J Biochem 2000; 267(24): 6972-6975.

42 Gordon T, Sulaiman O, Boyd JG. Experimental strategies to promote functional recovery after peripheral nerve injuries. J Peripher Nerv Syst 2003; 8(4): 236-250.

43 Sulaiman W, Dreesen TD. Effect of local application of transforming growth factor- $\beta$ at the nerve repair site following chronic axotomy and denervation on the expression of regeneration-associated genes. Laboratory investigation. J Neurosurg 2014; 121(4): 859-874.

44 Graham S, Leonidou A, Lester M et al. Investigating the role of PDGF as a potential drug therapy in bone formation and fracture healing. Expert Opin Investig Drugs 2009; 18(11): 1633-1654.

45 Yamazaki T, Sabit H, Oya T et al. Activation of MAP kinases, Akt and PDGF receptors in injured peripheral nerves. J Peripher Nerv Syst 2009; 14(3): 165-176.

46 Burnouf T, Goubran HA, Chen TM et al. Blood-derived biomaterials and platelet growth factors in regenerative medicine. Blood Rev 2013; 27(2): 77-89.

47 Hellman U, Malm L, Ma LP et al. Growth factor PDGF-BB stimulates cultured cardiomyocytes to synthesize the extracellular matrix component hyaluronan. PLoS One 2010; 5(12): e14393.

48 Mackenzie F, Ruhrberg C. Diverse roles for VEGF-A in the nervous system. Development 2012; 139(8): 1371-1380.

49 Hermann DM, Zechariah A. Implications of vascular endothelial growth factor for postischemic neurovascular remodeling. J Cereb Blood Flow Metab 2009; 29(10): 1620-1643.

50 Liang G, Cline GW, Macica CM. IGF-1 stimulates de novo fatty acid biosynthesis by Schwann cells during myelination. Glia 2007; 55(6): 632-641.

51 Nagata K, Itaka K, Baba M et al. Muscle-targeted hydrodynamic gene introduction of insulin-like growth factor-1 using polyplex nanomicelle to treat peripheral nerve injury. J Control Release 2014; 183: 27-34.

52 Grothe C, Nikkhah G. The role of basic fibroblast growth factor in peripheral nerve regeneration. Anat Embryol 2001; 204(3): 171-177.

53 Werner S, Grose R. Regulation of wound healing by growth factors and cytokines. Physiol Rev 2003; 83(3): 835-870.

54 Sawamura Y, Ikeda J, Miyamachi K et al. Full functional recovery after surgical repair of transected abducens nerve: case report. Neurosurgery 1997; 40(3): 605-607.

55 Kuffler DP, Reyes 0, Sosa IJ et al. Neurological recovery across a 12-cm-long ulnar nerve gap repaired 3.25 years post trauma: case report. Neurosurgery $2011 ; 69(6)$ : E1321-E1326.

56 Sánchez M, Yoshioka T, Ortega M et al. Ultrasound-guided platelet-rich plasma injections for the treatment of common peroneal nerve palsy associated with multiple ligament injuries of the knee. Knee Surg Sports Traumatol Arthrosc 2014; 22(5): 1084-1089.

57 Anitua E, Begoña L, Orive G. Treatment of hemimandibular paresthesia in a patient with bisphosphonate-related osteonecrosis of the jaw (BRONJ) by combining surgical resection and PRGF-Endoret. Br J Oral Maxillofac Surg 2013; 51(8): e272-e274.

58 Anjayani S, Wirohadidjojo YW, Adam AM et al. Sensory improvement of leprosy peripheral neuropathy in patients treated with perineural injection of plateletrich plasma. Int J Dermatol 2014; 53(1): 109-113.

59 Malahias MA, Johnson EO, Babis GC et al. Single injection of platelet-rich plasma as a novel treatment of carpal tunnel syndrome. Neural Regen Res 2015; 10(11): 1856-1859.

60 Khojasteh A, Hosseinpour S, Nazeman P et al. The effect of a platelet-rich fibrin conduit on neurosensory recovery following inferior alveolar nerve lateralization: a preliminary clinical study. Int J Oral Maxillofac Surg 2016; 45(10): 1303-1308.
61 Temmerman A, Vandessel J, Castro A et al. The use of leucocyte and platelet-rich fibrin in socket management and ridge preservation: a split-mouth, randomized, controlled clinical trial. J Clin Periodontol 2016; 43(11): 990-999.

62 Javaloy J, Alió JL, Rodriguez AE et al. Effect of platelet-rich plasma in nerve regeneration after LASIK. J Refract Surg 2013; 29(3): 213-219.

63 Luís AL, Amado S, Geuna S et al. Long-term functional and morphological assessment of a standardized rat sciatic nerve crush injury with a non-serrated clamp. J Neurosci Methods 2007; 163(1): 92-104.

64 Farrag TY, Lehar M, Verhaegen $\mathrm{P}$ et al. Effect of platelet rich plasma and fibrin sealant on facial nerve regeneration in a rat model. Laryngoscope $2007 ; 117(1)$ : 157-165.

65 Elgazzar RF, Mutabagani MA, Abdelaal SE et al. Platelet rich plasma may enhance peripheral nerve regeneration after cyanoacrylate reanastomosis: a controlled blind study on rats. Int J Oral Maxillofac Surg 2008; 37(8): 748-755.

66 Sariguney Y, Yavuzer R, Elmas C et al. Effect of platelet-rich plasma on peripheral nerve regeneration. J Reconstr Microsurg 2008; 24(3): 159-167.

67 Emel E, Ergün SS, Kotan D et al. Effects of insulin-like growth factor-I and platelet-rich plasma on sciatic nerve crush injury in a rat model. J Neurosurg 2011; 114(2): 522-528.

68 Lichtenfels M, Colomé L, Sebben AD et al. Effect of platelet rich plasma and platelet rich fibrin on sciatic nerve regeneration in a rat model. Microsurgery 2013; 33(5): 383-390.

69 Giannessi E, Coli A, Stornelli MR et al. An autologously generated platelet-rich plasma suturable membrane may enhance peripheral nerve regeneration after neurorraphy in an acute injury model of sciatic nerve neurotmesis. J Reconstr Microsurg 2014; 30(9): 617-626.

70 Kim JY, Jeon WJ, Kim DH et al. An inside-out vein graft filled with platelet-rich plasma for repair of a short sciatic nerve defect in rats. Neural Regen Res 2014; 9(14): 1351-1357.

71 Küçük L, Günay $\mathrm{H}$, Erbaş $\mathrm{O}$ et al. Effects of platelet-rich plasma on nerve regeneration in a rat model. Acta Orthop Traumatol Turc 2014; 48(4): 449-454.

72 Zheng C, Zhu Q, Liu X et al. Improved peripheral nerve regeneration using acellular nerve allografts loaded with platelet-rich plasma. Tissue Eng Part A 2014; 20(23/24): 3228-3240.

73 Abbasipour-Dalivand S, Mohammadi R, Mohammadi V. Effects of local administration of platelet rich plasma on functional recovery after bridging sciatic nerve defect using silicone rubber chamber: an experimental study. Bull Emerg Trauma 2015; 3(1): 1-7.

74 Firat C, Aytekin AH, Durak MA et al. Comparison of the effects of PRP and hyaluronic acid in promoting peripheral nerve regeneration An experimental study with vascular conduit model in rats'. Ann Ital Chir 2016; 87: 362-374.

75 Ding XG, Li SW, Zheng XM et al. The effect of platelet-rich plasma on cavernous nerve regeneration in a rat model. Asian J Androl 2009; 11(2): 215-221.

$76 \mathrm{Wu}$ CC, Wu YN, Ho $\mathrm{HO}$ et al. The neuroprotective effect of platelet-rich plasma on erectile function in bilateral cavernous nerve injury rat model. J Sex Med 2012; 9(11): 2838-2848.z

$77 \mathrm{Cho} \mathrm{HH}$, Jang S, Lee SC et al. Effect of neural-induced mesenchymal stem cells and platelet-rich plasma on facial nerve regeneration in an acute nerve injury model. Laryngoscope 2010; 120(5): 907-913.

78 Ye F, Li H, Qiao G et al. Platelet-rich plasma gel in combination with Schwann cells for repair of sciatic nerve injury. Neural Regen Res 2012; 7(29): 2286-2292.

79 Xie X, Zhao S, Wu H et al. Platelet-rich plasma enhances autograft revascularization and reinnervation in a dog model of anterior cruciate ligament reconstruction. J Surg Res 2013; 183(1): 214-222.

80 Zhao T, Yan W, Xu K et al. Combined treatment with platelet-rich plasma and brainderived neurotrophic factor-overexpressing bone marrow stromal cells supports axonal remyelination in a rat spinal cord hemi-section model. Cytotherapy 2013; 15(7): 792-804.

81 Qin J, Wang L, Zheng L et al. Concentrated growth factor promotes Schwann cell migration partly through the integrin $\beta 1$-mediated activation of the focal adhesion kinase pathway. Int J Mol Med 2016; 37(5): 1363-1370.

82 Piskin A, Kaplan S, Aktaş A et al. Platelet gel does not improve peripheral nerve regeneration: an electrophysiological, stereological, and electron microscopic study. Microsurgery 2009; 29(2): 144-153.

83 Kaplan S, Pişkin A, Ayyildiz M et al. The effect of melatonin and platelet gel on sciatic nerve repair: an electrophysiological and stereological study. Microsurgery 2011; 31(4): 306-313.

$84 \mathrm{Li} \mathrm{H}$, Han Z, Liu D et al. Autologous platelet-rich plasma promotes neurogenic differentiation of human adipose-derived stem cells in vitro. Int J Neurosci 2013; 123(3): 184-190.

85 Zheng C, Zhu Q, Liu X et al. Effect of platelet-rich plasma (PRP) concentration on proliferation, neurotrophic function and migration of Schwann cells in vitro. J Tissue Eng Regen Med 2016; 10(5): 428-436.

86 Sánchez M, Anitua E, Delgado $\mathrm{D}$ et al. Ultrasound-guided plasma rich in growth factors injections and scaffolds hasten motor nerve functional recovery in an ovine model of nerve crush injury. J Tissue Eng Regen Med 2015; e-pub ahead of print. doi:10.1002/term.2079.

87 Senses F, Önder ME, Koçyiğit ID et al. Effect of platelet-rich fibrin on peripheral nerve regeneration. J Craniofac Surg 2016; 27(7): 1759-1764.

88 Chan KM, Gordon T, Zochodne DW et al. Improving peripheral nerve regeneration: from molecular mechanisms to potential therapeutic targets. Exp Neurol 2014; 261: 826-835.

89 Wang James HC. Can PRP effectively treat injured tendons? Muscles Ligaments Tendons J 2014; 4(1): 35-37. 
90 Anitua E, Sánchez M, Orive G et al. Delivering growth factors for therapeutics. Trends Pharmacol Sci 2008; 29(1): 37-41.

91 Graziani F, Ivanovski S, Cei S et al. The in vitro effect of different PRP concentrations on osteoblasts and fibroblasts. Clin Oral Implants Res 2006; 17(2): 212-219.

92 Marx RE. Platelet-rich plasma: evidence to support its use. J Oral Maxillofac Surg 2004; 62(4): 489-496.

93 Nishida K, Suzuki T, Kakutani K et al. Gene therapy approach for disc degeneration and associated spinal disorders. Eur Spine J 2008; 17(Suppl 4): 459-466.

94 Zhang N, Wu YP, Qian SJ et al. Research progress in the mechanism of effect of PRP in bone deficiency healing. Scientific World Journal 2013; 2013: 134582.

95 Torabinejad M, Corr R, Buhrley $\mathrm{M}$ et al. An animal model to study regenerative endodontics. J Endod 2011; 37(2): 197-202.

96 Kaushik SN, Kim B, Walma AMC et al. Biomimetic microenvironments for regenerative endodontics. Biomater Res 2016; 20(1): 14

97 Dard M. Methods and interpretation of performance studies for dental implants. In: Boutrand JP (ed). Biocompatibility and Performance of Medical Devices. Oxford, UK Woodhead Publishing Ltd., 2012; 308-344.
98 Wancket LM. Animal models for evaluation of bone implants and devices: comparative bone structure and common model uses. Vet Pathol 2015; 52(5): 842-850.

99 Aerssens J, Boonen S, Lowet G et al. Interspecies differences in bone composition, density, and quality: potential implications for in vivo bone research. Endocrinology 1998; 139(2): 663-670.

(c) $($ i) $\ominus$ This work is licensed under a Creative Commons AttributionBY NC ND NonCommercial-NoDerivs 4.0 International License. The images or other third party material in this article are included in the article's Creative Commons license, unless indicated otherwise in the credit line; if the material is not included under the Creative Commons license, users will need to obtain permission from the license holder to reproduce the material. To view a copy of this license, visit http:// creativecommons.org/licenses/by-nc-nd/4.0/

(C) The Author(s) 2017 